\title{
Comparison of Antimicrobial Efficacy of Four Different Plant Extracts against Cariogenic Bacteria: An In Vitro Study
}

\author{
Amit Rai ${ }^{1}$, Abhay Mani Tripathi ${ }^{2}$, Sonali Saha ${ }^{3}$, Kavita Dhinsa ${ }^{4}$, Bhawana Jain ${ }^{5}$, Gunjan Yadav $^{6}$
}

\begin{abstract}
Background: Dental caries is an oral disease which is infectious in nature associated with various pathogenic microorganisms and is prevalent across the world.

Aim: To evaluate and compare the anticariogenic properties of the different plant extracts against various cariogenic microorganisms.

Materials and methods: In phase I, the anticariogenic efficacy of four different herbal extracts, namely Ocimum sanctum (Tulsi), Terminalia chebula (Harad), Tinospora cordifolia (Guduchi), and Glycyrrhiza glabra (Licorice), was evaluated against two strains of bacteria viz. Streptococcus mutans and Lactobacillus acidophilus. In the second phase of the study, the overall decay depth was compared.

Results: In phase I, zone of inhibition was significantly higher in G. glabra (Licorice) followed the descending order by O. sanctum (Tulsi), T. chebula (Harad), and T. cordifolia (Guduchi), respectively. In the second phase, it was found that the decay depth was significantly higher in T. cordifolia (Guduchi) followed the descending order by T. chebula (Harad), O. sanctum (Tulsi), and G. glabra (Licorice), respectively.

Conclusion: Glycyrrhiza glabra (Licorice) extract had potent antibacterial efficacy against S. mutans and L. acidophilus.

Clinical significance: Synthetic drugs have many adverse effects, so more attention has been paid to natural remedies because they are safe and effective. Today, the main interest is shifted toward the drugs which is derived from plants, which has led to the screening of many herbal plants for their potential antimicrobial activity and the same can be used clinically as an alternative of synthetic drugs used in dentistry.

Keywords: Dental caries, Glycyrrhiza glabra, Ocimum sanctum, Terminalia chebula.

International Journal of Clinical Pediatric Dentistry (2020): 10.5005/jp-journals-10005-1796
\end{abstract}

\section{INTRODUCTION}

The most common microbial disease affecting humans particularly children is dental caries. It is associated with various pathogenic microorganisms and is the most prevalent infectious oral disease across the world. ${ }^{1}$

Streptococcus mutans and Lactobacillus acidophilus are the most common etiological factor of dental caries. They can easily colonize on the surface of tooth and initiate acid production by synthesizing extracellular polysaccharides from sucrose foods. Hence, a caries prevention program primarily should be aimed at reducing the cariogenic bacteria. ${ }^{2}$

Many mouth rinses are available in market to control growth of cariogenic bacteria but mostly mouth rinses have drawbacks, such as alteration of taste, burning sensation and staining of teeth. This has necessitated the search for alternative mouth rinsing agents especially in children. The herbal preparations are considered as moderate in efficacy and are less toxic than the most commonly used pharmaceutical mouth rinses. ${ }^{3}$

Being a common and cheap remedy for the prevention and treatment of various diseases due to its incredible antimicrobial activity, Indian plants, such as Glycyrrhiza glabra (Licorice), T. cordifolia (Guduchi), Ocimum sanctum (Tulsi), and Terminalia chebula (Harad), have been used for this study. Hence, aim of the study was to evaluate and compare the anticariogenic properties of the different plant extracts against various cariogenic microorganisms.

\section{Materials and Methods}

The present study was carried out in the Department of Paediatrics and Preventive Dentistry, Sardar Patel Post Graduate Institute of Dental and Medical Sciences, in cooperation

\begin{abstract}
${ }^{1-6}$ Department of Pedodontics and Preventive Dentistry, Sardar Patel Postgraduate Institute of Dental and Medical Sciences, Lucknow, Uttar Pradesh, India

Corresponding Author: Amit Rai, Department of Pedodontics and Preventive Dentistry, Sardar Patel Postgraduate Institute of Dental and Medical Sciences, Lucknow, Uttar Pradesh, India, Phone: +919453268177, e-mail: dr.amitrai001@gmail.com

How to cite this article: Rai A, Tripathi AM, Saha S, et al. Comparison of Antimicrobial Efficacy of Four Different Plant Extracts against Cariogenic Bacteria: An In Vitro Study. Int J Clin Pediatr Dent 2020;13(4):361-367.
\end{abstract}

Source of support: Nil

Conflict of interest: None

with CSIR-Central Institute of Medicinal and Aromatic Plants, Lucknow, Uttar Pradesh, Department of Oral and Maxillofacial Pathology, Sardar Patel Post Graduate Institute of Dental and Medical Sciences and MM Diagnostics Lucknow, Uttar Pradesh.

The study was conducted in two phases. In phase I, the anticariogenic efficacy of four different herbal extracts, namely O. Sanctum (Tulsi), T. chebula (Harad), T. cordifolia (Guduchi), and G. glabra (Licorice), was evaluated against two strains of bacteria viz. S. mutans and L. acidophilus, known to be common etiological agents of dental caries, at different time interval using the agar diffusion test (ADT).

In the second phase of the study, the overall decay depth was compared after treatment with different herbal extracts, i.e., O. Sanctum (Tulsi), T. chebula (Harad), T. cordifolia (Guduchi), and G. glabra (Licorice) using polarized light microscope. 
Previously, a pilot study was conducted to review the proper study design and to check the possible limitations during the main study.

\section{Tested Microorganisms}

Following microorganisms are tested in the present study (Table 1).

\section{Tested Herbal Extracts (Table 2)}

Four herbal extracts used in this study were ethanolic extracts of O. Sanctum (Tulsi), T. chebula (Harad), T. cordifolia (Guduchi), and G. glabra (Licorice) (Fig. 1).

\section{Procurement of the Extract of the Three Plants}

The plant extracts were prepared according to the criteria of Central Institute of Medicinal and Aromatic Plants, Lucknow, Uttar Pradesh.

Herbal plants used in the study were picked up from market of Lucknow, Uttar Pradesh and taken to CIMAP-CSIR for preparation of herbal extracts. Used plants were cleaned, disinfected, washed lightly with the help of distilled water, and dried in shade. A coarse powder was prepared from the dried plant material. Two hundred grams of the powder were immersed in $500 \mathrm{~mL}$ of ethanol for 24 hours at room temperature and filtered through double layers of muslin cloth and the process of cold maceration has been repeated three times with fresh solvent using the same powdered drug. The filtrates were evaporated and using rotatory vacuum evaporator dried at $400^{\circ} \mathrm{C}$ under reduced pressure. The weighted extract yields were stored in the bottles at $50^{\circ} \mathrm{C}$.

Table 1: Microorganisms tested in the study

\begin{tabular}{lll}
\hline Microorganisms & Source & Morphotype \\
\hline Streptococcus mutans & ATCC 25175 & Gram-positive cocci \\
Lactobacillus acidophilus & ATCC 0885 & Gram-positive bacilli \\
\hline
\end{tabular}

Table 2: Herbal extracts used as anticariogenic agent in the study

\begin{tabular}{llllc}
\hline $\begin{array}{l}\text { Botanical } \\
\text { name }\end{array}$ & Family & $\begin{array}{l}\text { Common } \\
\text { name }\end{array}$ & $\begin{array}{l}\text { Plantspart } \\
\text { used }\end{array}$ & $\begin{array}{l}\text { Extract } \\
\text { yield (\%) }\end{array}$ \\
\hline $\begin{array}{l}\text { Glycyrrhiza } \\
\text { glabra }\end{array}$ & Leguminosae & Licorice & Twig & 8 \\
$\begin{array}{l}\text { Terminalia } \\
\text { chebula }\end{array}$ & Combretaceae & Harad & Fruit & 10 \\
$\begin{array}{l}\text { Tinospora } \\
\text { cordifolia } \\
\text { Ocimum } \\
\text { sanctum }\end{array}$ & $\begin{array}{l}\text { Menisper- } \\
\text { maceae }\end{array}$ & Guduchi & Leaves & 7 \\
\hline
\end{tabular}

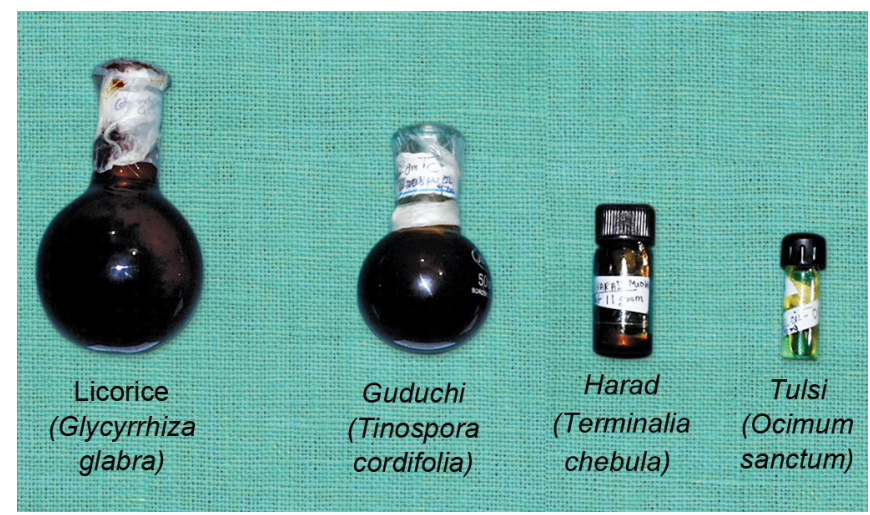

Fig. 1: Tested herbal extracts

\section{Essential Oil Extraction from Basils (O. sanctum)}

Basil leaves obtained from the Central Institute of Medicinal and Aromatic Plants, Lucknow were washed with distilled water. Clevenger apparatus were used to extract the essential oil by hydrodistillation method.

\section{Materials and Methods}

\section{Phase I: Culturing of Cariogenic Bacteria over Agar Plates Procedure}

Pure strains of S. mutans and L. acidophilus were taken, cultured in brain heart infusion agar (Himedia) and L. acidophilus in thioglycollate broth (Himedia), respectively. Lyophilized preparations of standard strains of above-mentioned bacteria were inoculated into combination of $1 \mathrm{~mL}$ of brain-heart infusion broth (BHI broth) and $1 \mathrm{~mL}$ of thioglycollate broth and incubated at $37^{\circ} \mathrm{C}$ in anaerobic chamber for 48 hours.

\section{Preparation of the Inoculum}

Inoculum for every bacterial strain was developed by taking four to five colonies with the help of the loop and dissolving them into respective test tube containing $5 \mathrm{~mL}$ of $0.85 \%$ saline solution to produce a turbidity of 0.5 on McFarland scale. This corresponds to a concentration of $10^{8}$ colony forming units $\mathrm{mL}^{-1}$. Petri dishes, $90-\mathrm{mm}$ diameter, containing 04-mm thick Mueller-Hinton agar ( $\mathrm{MH}$; Difco Laboratories, Detroit, Michigan, USA) were used for L. acidophilus and blood agar plates were used for S. mutans.

Sterile cotton swabs, dipped into the bacterial dilutions were applied smoothly on to the freshly prepared respective agar plates using the lawn technique to ensure even distribution of the inoculum. The inoculated agar plates were dried for 15 minutes at $37^{\circ} \mathrm{C}$ in an incubator. Every plate was divided into four equal parts. In every plate with the help of a sterilized and prefabricated copper wells, a well of 8-mm diameter was created. Each section has four wells, which are filled with the four different herbal extracts; the wells were filled with the herbal extracts until they were flushed with the surface of the agar medium in Petri dishes.

\section{Incubation}

To allow a good diffusion of the agents throughout the agar, the inoculated plates with the tested herbal extracts were maintained for 2 hours at room temperature. The $\mathrm{MH}$ agar plates inoculated with $L$. acidophilus were incubated in anaerobic chamber for 48 hours at $37^{\circ} \mathrm{C}$. In a $\mathrm{CO}_{2}$ incubator (Jouan, Saint Herblain, France) in an atmosphere of $10 \% \mathrm{CO}_{2}$, the blood agar plates inoculated with S. mutans strain were incubated.

After removing the plates from anaerobic chamber, diameter of the zone of inhibition around the wells was measured at the interval of 24,48 , and 72 hours (Fig. 2).

\section{Measuring the Size of Zone of Inhibition}

The plates for all the bacterial strains (facultative anaerobes) were examined for growth inhibitory zones around each tested herbal extracts as revealed by the absence of bacterial colonization.

\section{Phase II: To Check the Decay Depth after Treating with Different Anticariogenic Agents under Polarized Light Microscope}

Just after the extraction, in $0.9 \%$ normal saline solution, the teeth were placed and were kept in $10 \%$ solution of formalin for 


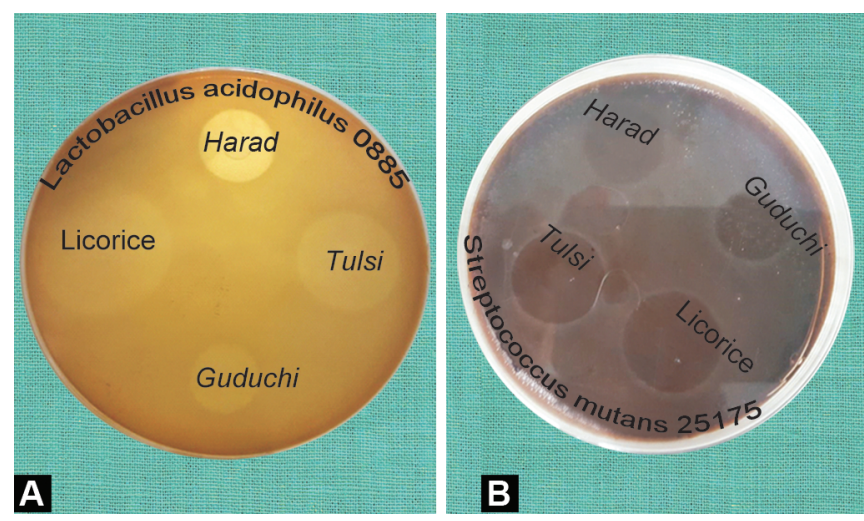

Figs $2 \mathrm{~A}$ and B: (A) Zone of inhibition of Lactobacillus acidophilus on thioglycollate agar plate; (B) Zone of inhibition of Streptococcus mutans on blood agar plate

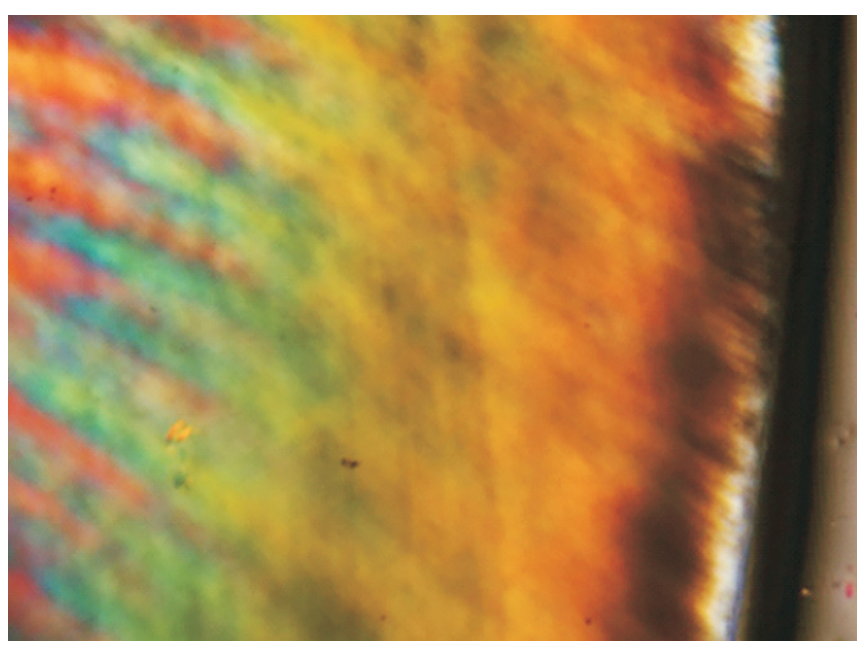

Fig. 3: Decay depth after treating with herbal extracts under polarized light microscope

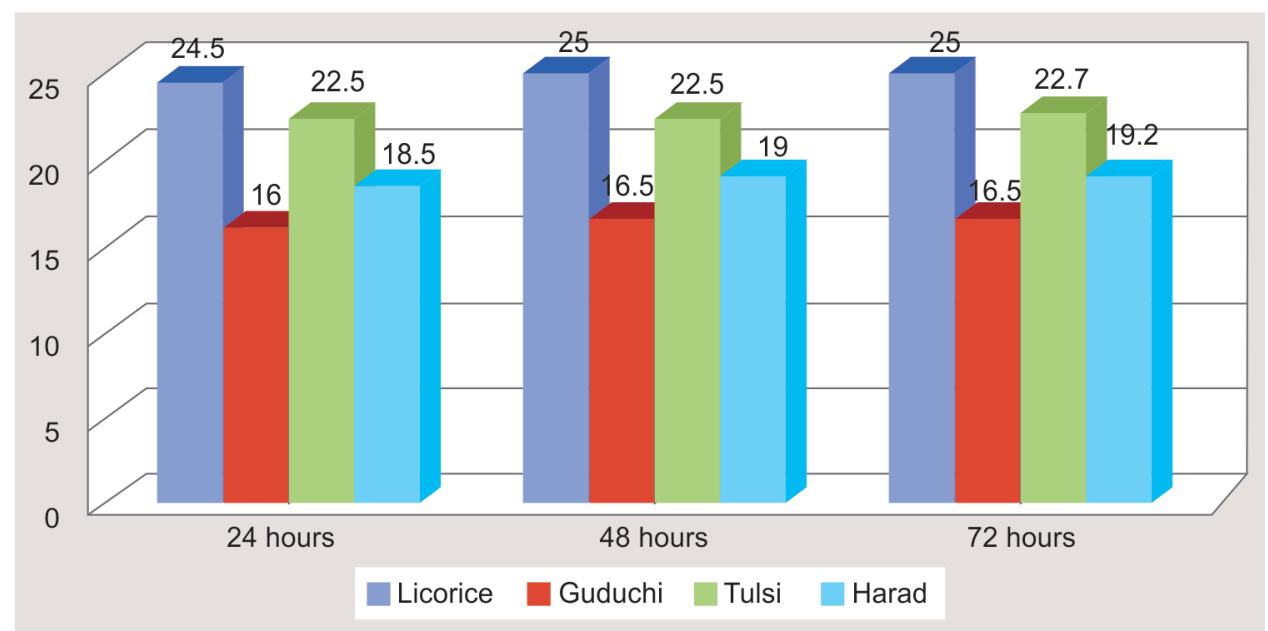

Fig. 4: Intergroup comparison of different tested herbal extracts for zone of inhibition against Streptococcus mutans

disinfection. After a week, with the help of periodontal curettes, the remaining soft dental tissue was removed and cleaning is performed using fluoride-free pumice and rubber caps. Teeth surfaces were covered using nail polish except a window of $3 \times$ $3 \mathrm{~mm}$ which is on the buccal surface then for sterilization teeth were kept in an autoclave at $121^{\circ} \mathrm{C}$ and a pressure of 15 pounds for 15 minutes. After that, teeth apices were sealed using sticky wax.

A BHI broth was used which is sterilized in an autoclave. In a tube which containing $5 \mathrm{~mL}$ of $\mathrm{BHI}$ broth, the prepared teeth were placed and then put inside an incubator at $37^{\circ} \mathrm{C}$ for 24 hours. Afterward, to make sure no contamination existed, the tubes were checked visually for turbidity. Artificial cariogenic media were added to every tube.

Based upon the study groups they belong to, the teeth were retrieved once every 24 hours and washed with the help of syringe with $5 \mathrm{~mL}$ of the anticariogenic study solutions for 21 days. After 21 days, the teeth were retrieved from the anticariogenic solution and prepared for demineralization depth studies (Fig. 3).

\section{Statistical Analysis}

All the statistical analyzes were performed using SPSS Version 21, IBM, USA. Normality of the data was evaluated using Shapiro-Wilk test. Data related to the zone of inhibition failed to satisfy the requirement of normality, while data related to decay depth was found to be normal in distribution.

Thus, inferential statistics of decay depth was performed using parametric tests of significance, i.e., one-way ANOVA, while inferential statistics of the zone of inhibition was performed using non-parametric tests of significance, i.e., Kruskal-Wallis test and Mann-Whitney U test. Statistical significance level was set at 0.05 .

\section{Results}

Figure 4 reveals the intergroup comparison of different tested herbal extracts for the zone of inhibition against $S$. mutans at 24 , 48 , and 72 hours. This was performed using one-way KruskalWallis test. Overall, a statistically significant difference was found between all four groups regarding the zone of inhibition at all the points of time.

Figure 5 reveals the intergroup comparison of the zone of inhibition against $L$. acidophilus among four test groups at 24,48 , and 72 hours. This was performed using one-way Kruskal-Wallis test. Overall, a statistically significant difference was found between all four groups regarding the zone of inhibition at all the points of time. 
Figure 6 reveals comparison of different tested herbal extracts for the zone of inhibition against S. mutans and L. acidophilus at different time intervals. Results showed no statistically significant difference could be found in the zone of inhibition between S. mutans and L. acidophilus with respect to four study groups at each point of time, i.e., 24,48 , and 72 hours.

Figure 7 reveals the intergroup comparison of decay depth among four test groups. This was performed using one-way ANOVA test. Overall, a statistically significant difference was found between all four groups regarding decay depth.

\section{Discussion}

Most individuals suffer at some time in their life from localized episodes of diseases in the mouth caused by the imbalance in the composition of their natural oral flora. ${ }^{4}$ These diseases include dental caries, periodontal diseases, and orodental diseases affecting human worldwide. ${ }^{5}$ There is many evidence which suggests that the main microorganisms which is responsible for dental caries is S. mutans, although additional acidogenic microorganisms, i.e., L. acidophilus also participate in the development of damages. ${ }^{6}$ These pathogens have capability to metabolize carbohydrates, to adhere on tooth surface, and to form a biofilm. Various studies on cariogenic microorganisms suggested that few natural products could affect the growth and virulence of S. mutans. ${ }^{7}$ For the prevention of these diseases, we can focus on increasing the ability of the host, decreasing the cariogenicity of the bacteria, and promoting less cariogenic diet. ${ }^{8}$ Therefore, for proper caries control, various methods should be followed with chemoprophylactic agents. Thus, we require a safe, effective, and economical treatment plan for the prevention of dental caries. Synthetic drugs have many adverse effects, so main focus is toward natural remedies which are safe as well as effective.

On screening various investigators discovered most effective therapeutic plant, i.e., G. glabra, T. cordifolia, O. sanctum, and T. chebula.

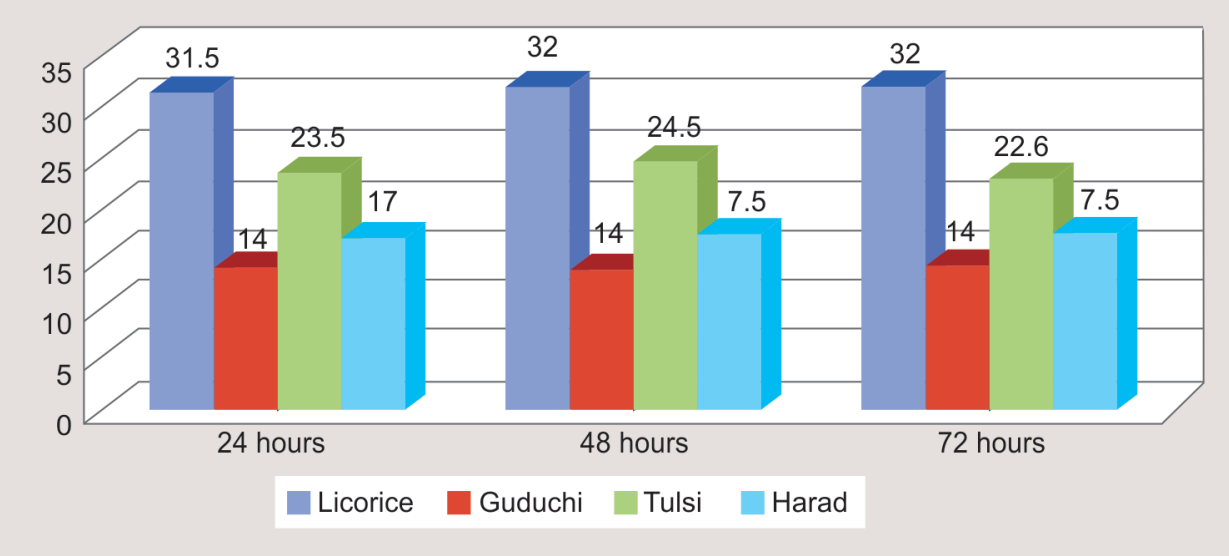

Fig. 5: Intergroup comparison of different tested herbal extracts for zone of inhibition against Lactobacillus acidophilus

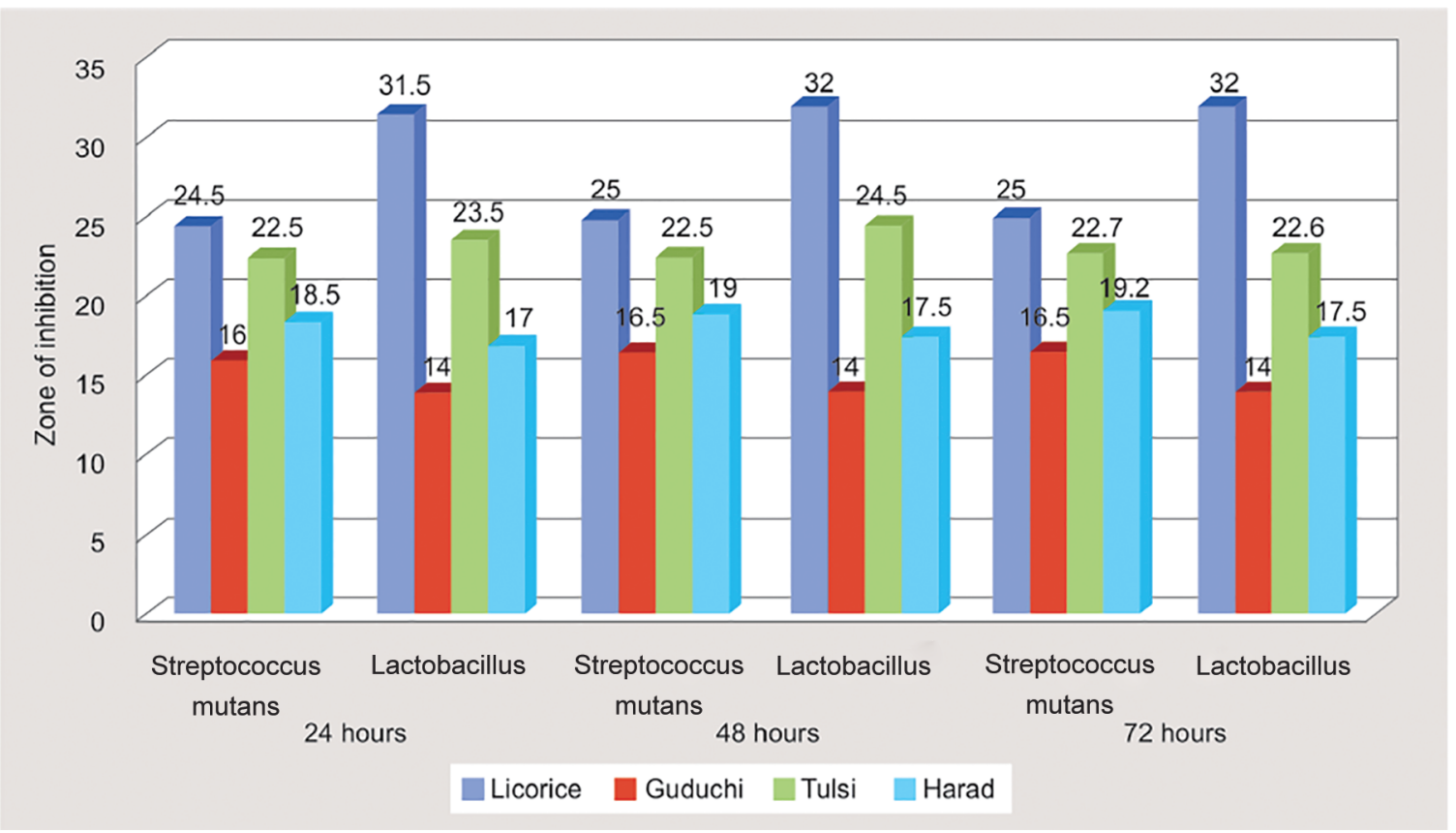

Fig. 6: Comparison of different herbal extracts for zone of inhibition against Streptococcus mutans and Lactobacillus acidophilus at various time intervals 


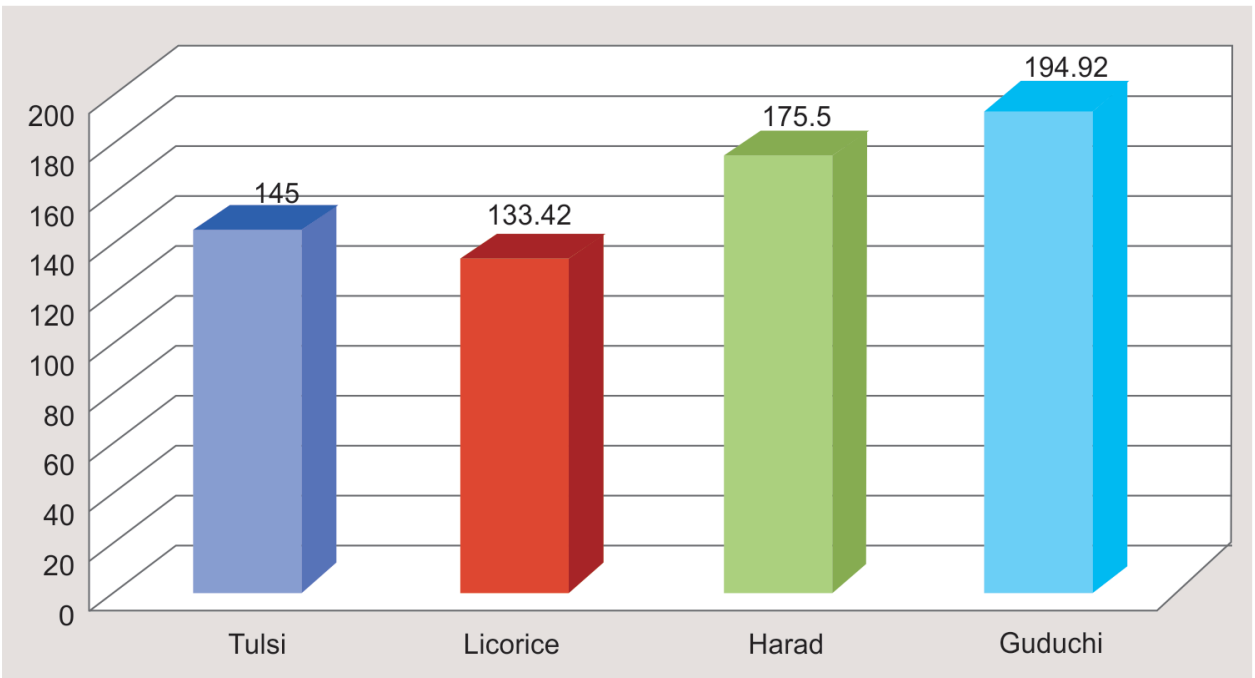

Fig. 7: Intergroup comparison of decay depth among the four tested herbal extracts

For this purpose, the anticariogenic efficacies of four herbal extracts were evaluated against two main cariogenic bacteria viz. S. mutans and L. acidophilus. These microorganisms are known as the most cariogenic species related to initial caries development. According to Caufield et al., recent concept of caries paradigm holds that acidogenic bacteria are responsible for dental caries which produce lactic acid due to the result of carbohydrate fermentation and their aciduric properties which is responsible for their survival in a low-pH milieu. ${ }^{9}$

Methanol, ethanol, and water are the commonly used solvents in investigations of antimicrobial activity of plants. However, methanolic extract is toxic, hence ethanolic extract was used as most of the constituents are well soluble in ethanol. ${ }^{10}$ As stated by Jain et al., the polar nature of the solvent, i.e., ethanol resulted in leaching of the active ingredients during extraction. ${ }^{11}$

Numerous studies have been performed to assess the antimicrobial efficacy using ADT.,12-16 It is one of the frequent and commonly used methods in vitro for assessing the antimicrobial efficacy. According to Ramachandra et al., ADT maintains the chemical properties of the tested extracts throughout the experimental period. The antibacterial agent diffusion through the agar gel in the ADT is controlled by the laws of diffusion. After different periods of exposure, the zones of inhibition diameter were measured because the diffusion of a critical inhibitory concentration of the antibacterial agent into the agar media and the bacteria meeting a particular density were time related, altering the size of zone of inhibition. ${ }^{17}$

After 7 days, periodontal curettes were used for removing of the remaining soft dental tissue and cleaned by fluoride-free pumice and rubber caps. Teeth surfaces were covered with nail polishexcept for a window of dimension $3 \times 3 \mathrm{~mm}$ which is on the buccal surface, for sterilization the teeth were placed in an autoclave at $121^{\circ} \mathrm{C}$ and a pressure of 15 pounds for 15 minutes. Similar technique for preparing the tooth was used by Jazaeri et al. Furthermore, every 2 days, a sample of cariogenic environment was cultivated to ensure the fact that the environment was microorganisms free that could affect the results of the study. ${ }^{18}$

Results of the present study showed that G. glabra (Licorice) has the largest inhibitory zones of microbial growth and minimum decay depth against $S$. mutans and L. acidophilus studied at all-time intervals. In case of microbial growth, G. glabra showed largest inhibitory zone followed by O. sanctum, T. chebula, and T. cordifolia.

Similar inhibitory activity of G. glabra (Licorice) has been reported by Jain et al., ${ }^{11}$ Rodino et al., ${ }^{19}$ Wang et al., ${ }^{20}$ and Awamie and Rees ${ }^{21}$ in their studies. Licorice has many advantageous effects on a number of mechanisms. Growth and cytopathology of numerous RNA and DNA viruses were affected by glycyrrhizin and glycyrrhizic acid including hepatitis $A$ and $C$, herpes zoster, HIV, herpes simplex, and cytomegalovirus. Glycyrrhizin and its metabolites also affect the hepatic metabolism of aldosterone and suppress 5-[beta] reductase. Glycyrrhetic acid and hormones secreted by the adrenal cortex have same structure accounts for the mineralocorticoid and glucocorticoid activity of glycyrrhizic acid.

According to Jain et al., this saponins glycoside, glycyrrhizin dose dependently inhibits the glucosyltransferase activity of S. mutans, which form a biofilm by the formation of insoluble glucans. The antibacterial action of saponins shows the involvement with membranolytic properties instead of altering the surface tension of the extracellular medium, therefore it is influenced by microbial population density. ${ }^{11}$

Results of the present study inferred that O. sanctum (Tulsi) produced the less inhibitory effect and more decay depth when compared to G. glabra (Licorice) and more inhibitory zones of microbial growth and less decay depth against S. mutans and L. acidophilus studied at all-time intervals than $T$. chebula and T. cordifolia, respectively.

As stated by Gadiyar et al., O. sanctum has essential or volatile oil which gives it a specific aromatic odor, mainly concentrated in the leaf. Phenols, terpenes, and aldehydes are mainly present in this aromatic volatile oil. Fixed oil is the oil which is extracted from seeds and mainly consist of fatty acids. Besides oil, there are presence of alkaloids, glycosides, saponins, and tannins. These have been associated with the antibacterial activity. ${ }^{22}$ MimicaDukic et al. observed that tannins has the antimicrobial properties which is related to their ability to inactivate microbial adhesions, enzymes, and cell envelope transport proteins, their complexity with polysaccharides, and their ability to modify the morphology of microorganism. ${ }^{23}$ Singhal et al. proposed that the antibacterial activity of $O$. sanctum (Tulsi) plant extract could be attributed to its ability to reduce silver ions to silver nanoparticles that have 
antibacterial properties against both gram-negative and grampositive bacteria. ${ }^{24}$ Nair et al. showed that Ocimum plant extract has a good inhibition against the five studied bacterial strains. This antimicrobial activity is due to attachment of the plant extract on the surface of the cell membrane which can alter the permeability and respiration functions of the cell. When plant extract interacts with microbial cytoplasmic components and nucleic acids, it inhibits the respiratory chain enzymes, alters the membrane permeability, and restricts the development of bacteria and yeasts. There are possibility that extract not only interact with the surface of membrane but also penetrate inside the bacteria. ${ }^{25}$

Results of the present study also stated that T. chebula produced the less inhibitory effect and more decay depth when compared to G. glabra (Licorice) and O. sanctum (Tulsi) and more inhibitory zones and less decay depth of microbial growth than T. cordifolia against S. mutans and L. acidophilus studied at all-time intervals.

The result of present study was similar to the studies of Agarwal et al. ${ }^{6}$ and Nayak et al., ${ }^{10}$ who stated that phytochemical analysis of the fruit powder showed the existence of constituents, such as tannins, glycosides and amino acids, anthraquinones, and polyphenolic compounds. Tannins have been assigned a number of activities including phagocytic cells stimulation, host-mediated tumor activity, and a wide range of anti-infective actions. Tannins are a group of polymeric phenolic substances and plant extract of T. chebula, with tannin as its active compound, is well recognized for its microbial activity and its astringent property. ${ }^{26}$

As reported by Kannan et al., ${ }^{27}$ alcoholic extracts have higher antimicrobial activity, there are two probability, either it is due to the properties of biological active components (alkaloids, flavonoids, essential oil, terpenoids, tannins, etc.), which may be increase in the presence of ethanol, or the stronger extraction capacity of ethanol that may have yielded a greater number of active constituents responsible for antibacterial activity. ${ }^{28}$

Results of the present study stated that $T$. cordifolia produced the least inhibitory effect and maximum decay depth when compared to G. glabra (Licorice), O. sanctum (Tulsi), and T. chebula (Harad) against S. mutans and L. acidophilus studied at all-time intervals. Tinospora cordifolia is a potent antimicrobial agent. This may be attributed to the fact that T. cordifolia only contains alkaloids, flavonoids, steroids, tannins, phenols, and saponins. ${ }^{29}$ According to Nagarprashanti et al., tannins and saponins are the only two active compounds that show antibacterial efficacy in comparison to other tested herbal extracts. ${ }^{30}$

\section{Conclusion}

In the first phase of the study, G. glabra (Licorice) showed the largest inhibitory zones of microbial growth against $S$. mutans and L. acidophilus studied at all-time intervals followed in decreasing order by O. sanctum (Tulsi), T. chebula (Harad), and T. cordifolia (Guduchi), respectively.

In the second phase of the study, the results of the measured overall decay depth reveal T. cordifolia (Guduchi) showed highest decay depth in descending order when compared to T. chebula (Harad), O. sanctum (Tulsi), and G. glabra (Licorice), respectively.

Further studies are recommended which is based on other factors effective in dental caries.

\section{Clinical Significance}

Synthetic drugs have many adverse effects, so more attention has been paid to natural remedies because they are safe and effective.
Today, the main interest is shifted toward the drugs which is derived from plants, which has led to the screening of many herbal plants for their potential antimicrobial activity and the same can be used clinically as an alternative of synthetic drugs used in dentistry.

\section{References}

1. Badr AE, Omar N, Badria FA. A laboratory evaluation of the antibacterial and cytotoxic effect of liquorice when used as root canal medicament. Int Endod J 2011;44(1):51-58. DOI: 10.1111/j.13652591.2010.01794.x

2. Velmurgan A, Madhubala MM, Bhavani S, et al. An in-vivo comparative evaluation of two herbal extracts Emblica officinalis and Terminalia chebula with chlorhexidine as an anticaries agent: a preliminary study. J Conservat Dent 2013;16(6):546-549. DOI: 10.4103/0972-0707. 120958.

3. Pai RK, Bhat SS, Salman A, et al. Use of an extract of Indian sacred plant Ocimum sanctum as an anticariogenic agent: An in vitro study. Int J Clin Pediatr Dent 2015;8(2):99-101. DOI: 10.5005/jp-journals-100051292.

4. Marsh PD, Martin MV. The resident oral microflora Martin PD, ed. Oral Microbiology. 5th ed., China: Elsevier Publisher; 2009.

5. Frencken JE, Sharma P, Stenhouse L, et al. Global epidemiology of dental caries and severe periodontitis - a comprehensive review. J Clin Periodontol 2017;44(18):94-105. DOI: 10.1111/jcpe.12677.

6. Agarwal P, Nagesh L, Murlikrishnan. Evaluation of the antimicrobial activity of various concentrations of Tulsi (Ocimum sanctum) extract against Streptococcus mutans: an in vitro study. Indian J Dent Res 2010;21(3):357-359. DOI: 10.4103/0970-9290.70800.

7. Rekha V, Jayamathi, Ramakrishnan, et al. Anticariogenic effect of Terminalia chebula. J Clin Diagnos Res 2014;8(8):51-54.

8. Ajagannanavar SL, Battur H, Shamarao S, et al. Effect of aqueous and alcoholic licorice (Glycyrrhiza glabra) root extract against Streptococcus mutans and Lactobacillus acidophilus in comparison to chlorhexidine: an in vitro study. J Int Oral Health 2014;6(4):29-34.

9. Caufield PW, Schon CN, Saraithong P, et al. Oral Lactobacilli and dental caries: A model for niche adaptation in humans. J Dent Res 2015;94(9):1-12. DOI: 10.1177/0022034515576052.

10. Nayak SS, Ankola AV, Metgud SC, et al. An in vitro study to determine the effect of Terminalia chebula extract and its formulation on Streptococcus mutans. J Contemp Dent Pract 2014;15(3):278-282. DOI: 10.5005/jp-journals-10024-1528.

11. Jain E, Pandey RK, Khanna R. Liquorice root extracts as potent cariostatic agents in pediatric practice. J Indian Soc Pedodont Prevent Dent 2013;31(3):146-152. DOI: 10.4103/0970-4388.117964.

12. Saha S, Samadi F, Jaiswal JN, et al. Antimicrobial activity of different endodontics sealer: an in vitro evaluation. J Indian Soc Pedodont Prevent Dent 2010;28(4):251-255. DOI: 10.4103/0970-4388.76151.

13. Shakouie S, Eskandarinezhad M, Sahi S, et al. Antimicrobial efficiency of AHPlus, adseal and endofill against Enterococcus faecalis - an in vitro study. Afr J Microbiol Res 2012;6(5):991-994.

14. Yamani HA, Pang EC, Mantri N, et al. Antimicrobial activity of Tulsi (Ocimum tenuiflorum) essential oil and their major constituents against three species of bacteria. Front Microbiol 2016;7:1-12. DOI: 10.3389/fmicb.2016.00681.

15. Chotvorrarak K, Yanpiset K, Banomyong D, et al. In vitro antibacterial activity of oligomer-based and calcium silicate-based root canal sealers. Mahidol Dental Journal 2017;37(2):145-154.

16. Rahman H, Chandra R, Chowdhary D, et al. Antimicrobial activity of MTA Fillapex, Real Seal SE, Acroseal and Zinc oxide eugenol sealers against enterococcus Faecalis and Candida Albicans. J Dent Med Sci 2017;16(1):66-69. DOI: 10.9790/0853-1601046669.

17. Ramachandra PKM, Krishnegowda SC, Jaganath BM, et al. In vitro comparative evaluation of the antibacterial and antifungal activities of different root canal sealers against endodontics pathogen. Int J Prevent Clin Dent Res 2016;3(4):261-266. DOI: 10.5005/ jp-journals-10052-0058. 
18. Jazaeri M, Pakdel F, Soufi LR, et al. Cariostatic effect of green tea in comparison with common anticariogenic agents: An in vitro study. J Dent Res Dent Clin Dent Prospects 2015;9(1):1-4. DOI: 10.15171/ joddd.2015.009.

19. Rodino S, Butu A, Butu M, et al. Comparative studies on antibacterial activity of licorice, elderberry and dandelion. Dig J Nanomat Biostruct 2015;10(3):947-955.

20. Wang L, Yang R, Yuan B, et al. The antiviral and antimicrobial activities of licorice, a widely-used Chinese herb. Acta Pharm Sin B 2015;5(4):310-315. DOI: 10.1016/j.apsb.2015.05.005.

21. Awamie ME, Rees $C$. Identification of the antimicrobial effect of liquorice extracts on gram-positive bacteria: determination of minimum inhibitory concentration and mechanism of action using a luxABCDE reporter strain. Int J Med Health, Biomed, Bioengineer Pharmaceut Engineer 2016;10(6):338-346.

22. Gadiyar A, Ankola AV, Rajpurohit L. Evaluation of the antimicrobial activity of Ocimum sanctum L. (Tulsi) extract against Streptococcus mutans and Lactobacillus acidophilus - an in vitro study. Int J Health Sci Res 2017;7(4):224-228.

23. Mimica-Dukic N, Kujundzic S, Sokovic M, et al. Essential oil composition and antifungal activity of Foeniculum vulgare mill obtained by different distillation conditions. Phytother Res 2003;17(4):368-371. DOI: 10.1002/ptr.1159.
24. Singhal G, Bhavesh R, Kasariya K, et al. Biosynthesis of silver nanoparticles using Ocimum sanctum (Tulsi) leaf extract and screening its antimicrobial activity. J Nanoparticle Res 2011;13(7):2981-2988. DOI: 10.1007/s11051-010-0193-y.

25. Nair SK, Shiva PBM. Holy herb Tulsi as a cure for oral and periodontal disease- a review. EC Dental Science 2017;10(4):106-109.

26. Carounanidy U, Satyanarayanan R, Velmurugan A. Use of an aqueous extract of Terminalia chebula as an anticaries agent: a clinical study. Indian J Dent Res 2007;18(4):152-156. DOI: 10.4103/0970-9290. 35823.

27. Kannan P, Ramadevi SR, Hopper W. Antibacterial activity of Terminalia chebula fruit extract. Afr J Microbiol Res 2009;3(4):180-184.

28. Ghosh S, Vandana KL, Thimmasetty J, et al. Tinospora cordifolia in the treatment of chronic and aggressive periodontitis patients with and without dental fluorosis: a clinical, microbiological, and biochemical study. Int J Oral Health Sci 2017;7(1):16-23. DOI: 10.4103/ ijohs.ijohs_62_16.

29. Vermani A, Navneet, Gautam SS. Screening of antibacterial activity of Tinospora cordifolia Miers. Extracts against dental pathogens. J Pharmacol Toxicol 2013;8(1):28-34. DOI: 10.3923/jpt.2013.28.34.

30. Nagaprashanthi CH, Rafi KP, Gopi CK, et al. In vitro antimicrobial activity of Tinospora cordifolia and its phytochemical screening. Int J Pharm Tech Res 2012;4(3):1004-1008. 